\title{
Desempenho da mamoneira IAC 2028 em função do espaçamento entre fileiras e população de plantas na safrinha
}

\author{
Genivaldo David de Souza-Schlick (1); Rogério Peres Soratto $\left(2^{*}\right)$; Coralie Bussamra Pasquali (3); \\ Adalton Mazetti Fernandes (')
}

(') Universidade Estadual Paulista "Júlio de Mesquita Filho" (FCA/UNESP), Programa de Pós-Graduação em Agronomia (Agricultura), Caixa Postal 237, 18603-970 Botucatu (SP).

(2) FCA/UNESP, Departamento de Produção Vegetal, 18603-970 Botucatu (SP).

(3) FCA/UNESP, Curso de Graduação em Agronomia, 18603-970 Botucatu (SP).

(*) Autor correspondente: soratto@fca.unesp.br

Recebido: 18/mai./2010; Aceito: 31/ago./2010

\begin{abstract}
Resumo
Com o lançamento de novas cultivares de mamona de porte baixo e frutos indeiscentes, adequadas para o cultivo mecanizado, faz-se necessário estabelecer adequados espaçamentos e populações de plantas para esses materiais, também em condições de safrinha. Assim, objetivou-se avaliar a influência do espaçamento entre fileiras e da população de plantas no desempenho da cultivar de mamona IAC 2028, no período de safrinha. O experimento foi realizado durante 2008 e 2009 , em Latossolo Vermelho distroférrico, em Botucatu (SP). O delineamento foi de blocos casualizados com parcelas subdivididas e quatro repetições. As parcelas foram constituídas por quatro espaçamentos entre fileiras (0,45, 0,60, 0,75 e 0,90 m) e as subparcelas por quatro populações iniciais de plantas (25.000, 40.000, 55.000 e 70.000 plantas ha $^{-1}$ ). Nos espaçamentos entre fileiras mais largos constatou-se menor crescimento das plantas e valores reduzidos de número de racemos por planta, número de frutos por racemo, produtividade de grãos e produtividade de óleo. Nas populações de plantas mais elevadas foram contatadas menor produção de matéria seca da parte aérea, diâmetro do caule, componentes da produção e maiores alturas de inserção do primeiro racemo. A produtividade de grãos foi pouco influenciada pelas populações de plantas estudadas, especialmente nos menores espaçamentos entre fileiras. As produtividades mais elevadas da mamoneira cultivar IAC 2028 na safrinha foram obtidas com os espaçamentos entre fileiras mais estreitos. É possível o cultivo da mamoneira de ciclo curto IAC 2028 na safrinha, na região de Botucatu (SP), nos espaçamentos entre fileiras de 0,45 e 0,60 m.
\end{abstract}

Palavras-chave: Ricinus communis, arranjo espacial, densidade de plantas, produtividade de grãos, teor de óleo.

\section{Castor bean IAC 2028 performance as affected by row spacing and plant population in out-of-season cropping}

\begin{abstract}
With the release of new low height castor bean cultivars with indehiscent fruit and suitable for mechanized cultivation, it is necessary to establish adequate row spacing and plant population for these materials. Thus, the objective of this study was to evaluate row spacing and plant population influence on the performance of castor bean cultivar IAC 2028 in out-of-season cropping. The experiment was carried out in 2008 and 2009, on a Haplorthox in Botucatu county, State of São Paulo, Brazil. A randomized complete block design was used in a split-plot scheme with four replications. The plots were composed by four row spacings $(0.45,0.60,0.75$ and $0.90 \mathrm{~m})$ and subplots comprised four initial plant populations $(25,000,40,000,55,000$, and 70,000 plants $\left.\mathrm{ha}^{-1}\right)$. The largest row spacing provided the lower plant growth, number of racemes per plant, number of fruits per raceme, grain and oil yields. The highest plant populations provided smaller aboveground dry matter, stem diameter, yield components, and higher height of the first raceme insertion. Grain yield was little affected by plant populations, mainly in small row spacings. The smallest row spacings provided higher grain yields of castor bean cultivar IAC 2028 in out-of-season cropping, being recommended 0.45 and 0.60 m row spacings.
\end{abstract}

Key words: Ricinus communis, spatial arrangement, plant density, grain yield, oil content. 


\section{INTRODUÇÃO}

O Brasil já foi o maior produtor mundial de mamona (Ricinus communis L.) e exportador do óleo extraído dos grãos desta oleaginosa. Atualmente, o país é o $3 .^{\circ}$ maior produtor (FAO, 2009), com produção de aproximadamente 120 mil toneladas na safra de $2007 / 2008$, porém, com produtividade média ainda reduzida, cerca de $760 \mathrm{~kg}$ ha $^{-1}$ (ConAB, 2010).

Com o lançamento de cultivares com grande potencial produtivo, precocidade, amadurecimento uniforme, pouca deiscência, elevado teor de óleo, resistência a pragas e doenças e porte baixo, que são adequados à colheita mecânica (Freire et al., 2007; SAVY FilHo et al., 2007), a cultura da mamona passou a ser interessante também para médios e grandes produtores, inclusive como opção para rotação de culturas, no período de safrinha, no qual a viabilidade de outras culturas pode ser comprometida pela limitação hídrica, já que se constata relativa tolerância à deficiência hídrica na mamoneira (SAVY Filho, 2005). Porém, no cultivo em grande escala são exigidas tecnologias mais eficientes para que seja expresso o potencial produtivo do material.

Para qualquer cultura, o conhecimento da combinação ótima do espaçamento entre fileiras e da densidade de plantas na fileira é essencial para a maximização econômica da produçáo (Henderson et al., 2000), sendo uma das tecnologias de mais simplicidade de aplicação (SEverino et al., 2006a). Entretanto, o arranjo adequado de plantas é dependente de características intrínsecas da cultivar, como porte, hábito de crescimento e arquitetura de planta $(\mathrm{BE}-$ ZERRA et al., 2009), bem como das condições edafoclimáticas e do sistema de manejo (Severino et al., 2006a,c).

Para a mamoneira de porte baixo, a definição da população de plantas e o espaçamento entre fileiras ideais é um aspecto complexo (Severino et al., 2006a; Azevedo et al., 2007). Segundo os autores, no material disponibilizado no mercado há grande variação no hábito de crescimento e no desempenho quanto às condiçóes de cultivo. Em densidades populacionais elevadas são proporcionadas plantas muito altas e sujeitas ao acamamento. Por outro lado, com populaçóes menos densas é facilitada a infestação de plantas daninhas e a formação de plantas com floração tardia e ramos laterais longos, sendo inviabilizada a colheita mecanizada (SEVERINo et al., 2006c).

Além da competição por luz e nutrientes, um dos fatores de mais influência na definição do espaçamento e da população de plantas mais adequados para a mamoneira de porte baixo é a disponibilidade hídrica (CANECCHio Filho e Freire, 1959; Кittock e Williams, 1970; Azevedo et al., 2007). Canecchio Filho (1954), com base na análise conjunta de 16 experimentos, em diversas localidades do Estado de São Paulo, concluiu que, com mais densidade populacional na fileira, no espaçamento entre fileiras de $1,0 \mathrm{~m}$, foram proporcionados maiores valores de produtivi- dade da mamoneira anã IAC-38. Para Canecchio Filho e Freire (1959), em condiçôes favoráveis de chuva, nos espaçamentos mais estreitos (mais plantas por área) foram obtidas produtividades mais elevadas; já em condiçôes de deficiência hídrica, dessa mesma situação não ocorreu elevada produtividade, mesmo em solo de muita fertilidade. Segundo Kiтtock e Williams (1970), a população ideal de plantas para a mamoneira de porte baixo, em condiçôes irrigadas, foi de 58.000 plantas $\mathrm{ha}^{-1}$, enquanto em condiçôes de sequeiro, a populaçáo ideal foi próxima de 30.000 plantas $\mathrm{ha}^{-1}$, no espaçamento entre fileiras de 1,02 $\mathrm{m}$. No Brasil, na maioria dos estudos com a mamoneira foram utilizados espaçamentos com largura mínima de 1,0 $\mathrm{m}$ e populaçôes reduzidas de plantas (CANeCCHio Filho, 1954; Canecchio Filho e Freire, 1959; SeVerino et al., 2006a, c). Assim, ainda existem muitas dúvidas a respeito do desempenho das cultivares de mamona de porte baixo recentemente lançadas, quando cultivadas no período de safrinha, em espaçamentos entre fileiras mais estreitos e populaçôes de plantas mais elevadas que os tradicionalmente utilizados para a cultura.

Nesse contexto, objetivou-se, neste trabalho, avaliar a influência do espaçamento entre fileiras e da população de plantas no crescimento e na produtividade da cultivar de mamona IAC 2028, no período de safrinha.

\section{MATERIAL E MÉTODOS}

O experimento foi realizado no município de Botucatu,

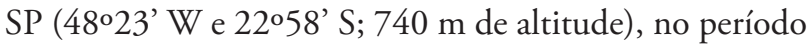
de safrinha (outono-inverno) de 2008 e 2009. O clima é do tipo Cwa (Köppen), que se caracteriza como tropical de altitude, com inverno seco, verão quente e chuvoso. Os dados climáticos registrados durante o desenvolvimento do experimento estão apresentados na figura 1 .

O solo da área experimental é Latossolo Vermelho distroférrico (EMBrapa, 2006). Antes da instalação do experimento, em cada ano, foram coletadas amostras de solo na profundidade de $0-0,20 \mathrm{~m}$, para caracterização química (RAIJ et al., 2001). Em 2008 os resultados foram: matéria orgânica: $38 \mathrm{~g} \mathrm{dm}^{-3}, \mathrm{pH}\left(\mathrm{CaCl}_{2}\right): 5,0, \mathrm{P}$ (resina): 39 mg dm${ }^{-3}, \mathrm{~K}, \mathrm{Ca}, \mathrm{Mg}$ e CTC: 4,1, 31, 9 e $95 \mathrm{mmol}_{\mathrm{c}} \mathrm{dm}^{-3}$ respectivamente e saturaçấo por bases de $46 \%$. Na área utilizada em 2009 os resultados foram: matéria orgânica: $40 \mathrm{~g} \mathrm{dm}^{-3}, \mathrm{pH}\left(\mathrm{CaCl}_{2}\right):$ 5,6, P (resina): $26 \mathrm{mg} \mathrm{dm}^{-3}, \mathrm{~K}$, $\mathrm{Ca}, \mathrm{Mg}$ e CTC: 2,6, 43, 22 e $97 \mathrm{mmol}_{\mathrm{c}} \mathrm{dm}^{-3}$ respectivamente e saturação por bases de $70 \%$.

O delineamento experimental foi o de blocos casualizados, em esquema de parcela subdividida, com quatro repetiçóes. As parcelas foram constituídas por quatro espaçamentos entre fileiras $(0,45,0,60,0,75$ e $0,90 \mathrm{~m})$ e as subparcelas por quatro populaçóes de plantas (25.000, $40.000,55.000$ e 70.000 plantas ha $\left.^{-1}\right)$. Cada unidade experimental foi constituída por 10, 6, 6 e 6 fileiras nos 
espaçamentos de, respectivamente, $0,45,0,60,0,75 \mathrm{e}$ $0,90 \mathrm{~m}$ e $5 \mathrm{~m}$ de comprimento. Para as avaliaçóes foram consideradas as linhas centrais, desprezando $0,5 \mathrm{~m}$ na extremidade de cada fileira de plantas e uma fileira de cada lado da unidade experimental.

A cultivar IAC 2028, obtida por meio da hibridação artificial entre a linhagem L881, desenvolvida por seleção massal dentro da cultivar IAC-38, e a progênie H34, é bem adaptada às condiçóes edafoclimáticas do Estado de São Paulo, de porte baixo (150-180 cm), frutos indeiscentes, moderada suscetibilidade a doenças, em especial ao fungo mofo-cinzento (Botryotinia ricini, (Goldf.) Wet), teor de óleo em torno de $47 \%$ e ciclo precoce, variável de 150 a 180 dias, produtividade média de gráos de $2.000 \mathrm{~kg} \mathrm{ha}^{-1}$, sendo adequada para colheita mecanizada com automotriz (SAVY FilHo et al., 2007).

Em 20/2/08 e 23/2/2009 as plantas presentes na área foram dessecadas mediante a aplicaçáo de herbicida glifosate na dose de $1.440 \mathrm{~g} \mathrm{ha}^{-1}$ do i.a. A instalaçáo do experimento foi realizada em sistema plantio direto. A abertura dos sulcos e distribuiçấo do adubo foi realizada com uma semeadora-adubadora tratorizada, regulada de acordo com o espaçamento. A adubação básica de semeadura constou da aplicação, em todos os tratamentos, de $150 \mathrm{~kg} \mathrm{ha}^{-1} \mathrm{da}$ fórmula-NPK 08-28-16, seguindo as recomendaçóes de Savy FilHo (1996).

A semeadura foi realizada manualmente em 8/3/08 e 10/3/2009, colocando-se no sulco as quantidades de sementes necessárias para a obtenção do dobro das populaçóes de plantas pretendidas para cada tratamento. As sementes foram tratadas com o fungicida carboxin+tiram $(60+60 \mathrm{~g}$ do i.a por $100 \mathrm{~kg}$ de sementes $)$ e com o inseticida tiametoxam ( $140 \mathrm{~g}$ do i.a. por $100 \mathrm{~kg}$ de sementes). A emergência das plântulas ocorreu em 18/3/08 e 20/3/09. Aos 10 dias após a emergência (DAE) foi realizado o desbaste deixando-se a populaçáo de plantas planejada para cada tratamento.

A adubação de cobertura foi realizada aos $30 \mathrm{DAE}$, aplicando-se $60 \mathrm{~kg} \mathrm{ha}^{-1}$ de $\mathrm{N}$, na forma de sulfato de amônio.

Durante todo o período de desenvolvimento da mamona foram realizadas capinas manuais para o controle das plantas infestantes na área. O controle preventivo do mofo-cinzento foi realizado mediante aplicaçôes dos fungicidas a partir do início do florescimento.

No início do florescimento (27/5/2008 e 30/5/2009) foi determinada a massa de matéria seca da parte aérea das plantas, coletando-se cinco plantas por parcela e secando-as em estufa com circulaçáo forçada de ar a $70^{\circ} \mathrm{C}$, por 72 horas.

As colheitas foram realizadas em 9/9/2008 e 28/9/2009. Nesta ocasiāo foram avaliados: diâmetro do caule (no primeiro internódio da planta), altura de planta (distância entre o solo e o ponto mais alto da planta), altura de inserção do $1 .^{\circ}$ racemo (distância entre o solo e o ponto de inserção do racemo), população final de plantas; número de racemos por planta, número de frutos por racemo, número médio (a)

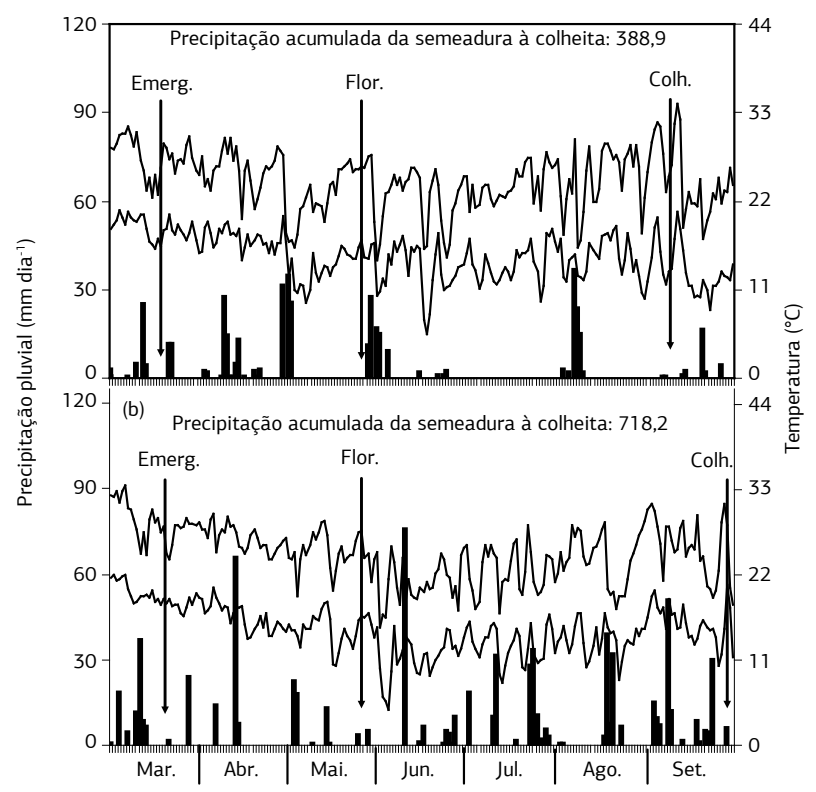

Figura 1. Precipitação pluvial (ا), temperaturas máxima e mínima (_), obtidas na área do experimento, durante o período de março a setembro, nos anos 2008 (a) e 2009 (b), e datas de emergência, inicio do florescimento e colheita da mamoneira cultivar IAC 2028. Botucatu (SP).

de grãos por fruto, massa de cem grãos e produtividade de grãos, em kg ha ${ }^{-1}$ (13\% de umidade).

Após a colheita os grãos foram secados em estufa com circulação forçada de ar a $70^{\circ} \mathrm{C}$, por 24 horas e determinado o teor de óleo (base seca), por ressonância magnética nuclear, e a produtividade de óleo, em $\mathrm{kg} \mathrm{ha}^{-1}$.

Os dados foram submetidos à análise de variância, segundo o esquema de análise conjunta de experimentos em parcelas subdivididas (CAmpos, 1984). O fator espaçamento entre fileiras foi considerado qualitativo, enquanto a população de plantas foi considerada fator quantitativo. Assim, as médias referentes aos espaçamentos foram comparadas pelo teste Tukey $(p \leq 0,05)$, enquanto os efeitos das populações de plantas foram avaliados por meio de análise de regressáo, adotando-se como critério para escolha do modelo a magnitude dos coeficientes de regressão significativos $(\mathrm{p}<0,05)$. Foram realizadas análises de correlação simples entre as características agronômicas da cultura da mamona, visando determinar o grau de associação entre elas.

\section{RESULTADOS E DISCUSSÃO}

Como as interações ano x espaçamento, ano x população de plantas ou ano $\mathrm{x}$ espaçamento $\mathrm{x}$ populaçáo de plantas na análise conjunta foram significativas para a maioria das variáveis estudadas, optou-se por analisar os efeitos de espaçamento entre fileiras e população de plantas em cada ano separadamente. 
Praticamente não houve diferenças entre as populaçôes de plantas previamente estabelecidas e as obtidas na colheita (Tabela 1). Para Rocha et al. (1964), com o aumento da população de plantas, ou mais especificamente com o adensamento das plantas na fileira, é proporcionada redução da população final de plantas. Contudo, tal efeito não foi observado no presente experimento.

Houve influência do espaçamento entre fileiras e da população de plantas na massa de matéria seca da parte aérea, nos dois anos (Tabela 2). Em 2008, os maiores valores $(71,7$ e 73,3 g) de matéria seca foram observados nos espaçamentos mais estreitos $(0,45$ e $0,60 \mathrm{~m})$. No segundo ano, a produção de matéria seca da parte aérea $(56,6 \mathrm{~g})$ mais elevada foi proporcionada no espaçamento de 0,90 $\mathrm{m}$ entre fileiras, porém, sendo diferente apenas daquela obtida no espaçamento de $0,75 \mathrm{~m}$, em que o valor médio foi de 47,8 g. Com o aumento da população de plantas houve decréscimo na produção de matéria seca da parte aérea, em ambos os anos (Figura 2a,b). A produção de matéria seca mais elevada na população de 25.000 plantas $\mathrm{ha}^{-1}$ foi em função do maior crescimento das plantas, que, provavelmente, foi favorecido pela menor competiçáo entre elas, resultando em maior crescimento individual. Com o aumento da população de plantas na área é reduzida a distância entre as plantas na fileira e, consequentemente, aumentada a competição por fatores ambientais

Tabela 1. População final de plantas na colheita da mamoneira cultivar IAC 2028 em função do espaçamento entre fileiras e da população inicial de plantas, na safrinha. Botucatu (SP), 2008 e 2009

\begin{tabular}{|c|c|c|c|c|c|}
\hline \multirow{4}{*}{ População inicial } & \multicolumn{4}{|c|}{ Espaçamento (m) } & \multirow{2}{*}{ Média } \\
\hline & 0,45 & 0,60 & 0,75 & \multirow[t]{2}{*}{0,90} & \\
\hline & \multicolumn{4}{|c|}{ plantas ha-1 } & \\
\hline & \multicolumn{5}{|c|}{2008} \\
\hline 25.000 & 25.000 & 25.000 & 25.000 & 25.000 & $25.000(100 \%)^{(1)}$ \\
\hline 40.000 & 40.000 & 40.000 & 40.000 & 40.000 & 40.000 (100\%) \\
\hline 55.000 & 52.500 & 55.000 & 55.000 & 55.000 & 54.375 (98,9\%) \\
\hline \multirow[t]{2}{*}{70.000} & 70.000 & 70.000 & 69.998 & 70.000 & 70.000 (100\%) \\
\hline & \multicolumn{5}{|c|}{2009} \\
\hline 25.000 & 25.000 & 25.000 & 24.972 & 25.000 & 24.993 (99,9\%) \\
\hline 40.000 & 40.000 & 39.972 & 39.611 & 39.870 & 39.863 (99,6\%) \\
\hline 55.000 & 55.000 & 55.000 & 54.917 & 54.806 & 54.930 (99,8\%) \\
\hline 70.000 & 66.667 & 69.444 & 69.444 & 66.667 & $68.055(97,2 \%)$ \\
\hline
\end{tabular}

(1) Valores entre parênteses são indicativos da população final de plantas, em porcentagem da população inicialmente estabelecida.

Tabela 2. Matéria seca da parte aérea, diâmetro do caule, altura da planta, altura de inserção do $1 .^{\circ}$ racemo e número de racemos por planta da mamoneira cultivar IAC 2028 em função do espaçamento entre fileiras e populaçáo de plantas, na safrinha. Botucatu (SP), 2008 e 2009

\begin{tabular}{|c|c|c|c|c|c|c|c|c|c|c|}
\hline \multirow[t]{2}{*}{ Tratamentos } & \multicolumn{2}{|c|}{ Matéria seca } & \multicolumn{2}{|c|}{ Diâmetro do caule } & \multicolumn{2}{|c|}{ Altura da planta } & \multicolumn{2}{|c|}{$\begin{array}{c}\text { Altura de inserção } \\
\text { do } 1 .^{\circ} \text { racemo }\end{array}$} & \multicolumn{2}{|c|}{$\begin{array}{c}\text { Racemos por } \\
\text { planta }\end{array}$} \\
\hline & 2008 & 2009 & 2008 & 2009 & 2008 & 2009 & 2008 & 2009 & 2008 & 2009 \\
\hline Espaçamento (m) & \multicolumn{2}{|c|}{ g planta $^{-1}$} & \multicolumn{2}{|c|}{$\mathrm{mm}$} & \multicolumn{4}{|c|}{$\mathrm{m}$} & \multicolumn{2}{|c|}{ número } \\
\hline 0,45 & $71,7 a$ & $50,3 a b$ & $24,1 \mathrm{ab}$ & $23,1 \mathrm{a}$ & $1,43 a$ & $1,27 b$ & $0,71 a$ & $0,52 a$ & $1,7 \mathrm{a}$ & $1,8 \mathrm{a}$ \\
\hline 0,60 & $73,3 a$ & $49,2 \mathrm{ab}$ & $25,3 a$ & $23,1 \mathrm{a}$ & $1,46 a$ & 1,30ab & 0,69a & $0,54 a$ & $1,7 \mathrm{a}$ & $1,6 \mathrm{ab}$ \\
\hline 0,75 & $59,9 b$ & $47,8 b$ & $22,6 b$ & $23,2 \mathrm{a}$ & $1,30 b$ & $1,28 b$ & $0,60 b$ & $0,58 a$ & $1,6 a$ & 1,6ab \\
\hline 0,90 & $59,6 b$ & $56,6 a$ & $23,3 a b$ & $23,4 a$ & $1,30 b$ & $1,36 a$ & 0,60b & $0,62 a$ & $1,6 a$ & $1,4 b$ \\
\hline \multicolumn{11}{|l|}{ Teste F } \\
\hline Espaçamento (E) & $12,96^{* *}$ & $4,66^{*}$ & $5,13^{*}$ & $0,49 n s$ & $12,04^{* *}$ & $7,01^{* *}$ & $18,31^{* *}$ & $2,94 \mathrm{~ns}$ & $0,29 \mathrm{~ns}$ & $6,722^{*}$ \\
\hline \multicolumn{11}{|c|}{ População inicial (P) } \\
\hline Reg. Quadrática & $18,55^{* *}$ & $10,46^{* *}$ & $9,43^{* *}$ & $51,28^{* *}$ & $12,19^{* *}$ & $0,66 n s$ & $1,46 \mathrm{~ns}$ & $1,65 \mathrm{~ns}$ & $47,17^{* *}$ & $1,44 \mathrm{~ns}$ \\
\hline$E \times P$ & 1,80 ns & $1,39 \mathrm{~ns}$ & $1,79 \mathrm{~ns}$ & $1,96 \mathrm{~ns}$ & $2,03 n s$ & $2,78^{*}$ & $1,10 \mathrm{~ns}$ & $0,86 n s$ & $1,02 \mathrm{~ns}$ & $12,49 * *$ \\
\hline$C V_{\text {parcela }}(\%)$ & 12,5 & 14,2 & 8,6 & 3,5 & 6,9 & 4,5 & 8,2 & 17,6 & 16,5 & 14,9 \\
\hline $\mathrm{CV}_{\text {subparcela }}(\%)$ & 13,1 & 13,7 & 6,1 & 3,2 & 5,2 & 3,5 & 8,5 & 10,8 & 16,6 & 12,8 \\
\hline
\end{tabular}

Médias seguidas de letras distintas, na coluna, dentro do fator espaçamento, são diferentes estatisticamente pelo teste de Tukey $(\mathrm{p} \leq 0,05) .{ }^{*}=\mathrm{p}<0,05 \mathrm{e}^{* *}=\mathrm{p}<0,01 . \mathrm{ns}=$ não significativo 

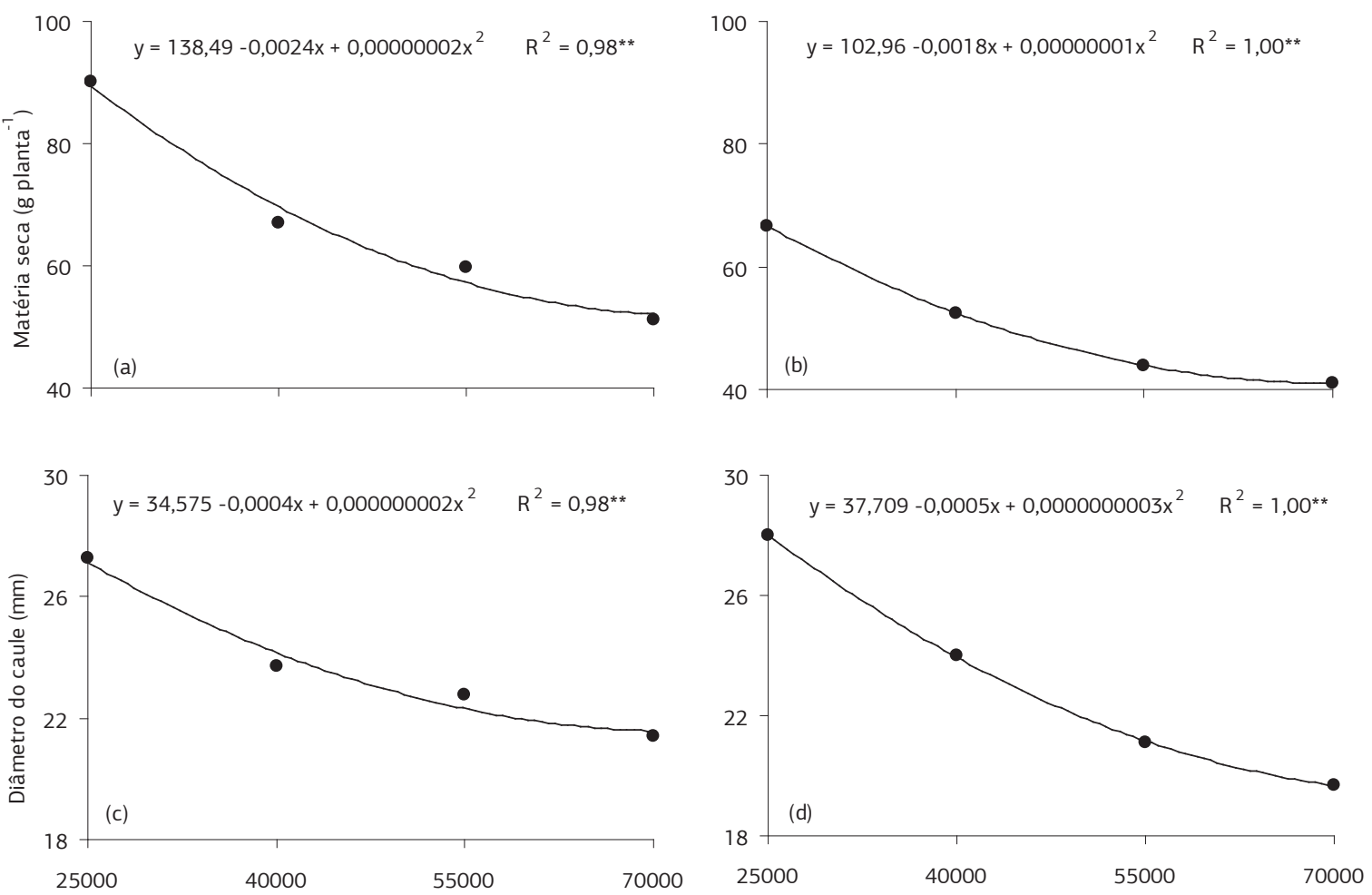

População inicial (plantas ha־1)

Figura 2. Matéria seca da parte aérea $(a, b)$ e diâmetro do caule $(c, d)$ da mamoneira cultivar IAC 2028 em função da população de plantas e espaçamentos entre fileiras, na safrinha. Botucatu (SP), 2008 (a,c) e 2009 (b,d). ${ }^{* *}$ p <0,01.

(água, luz e nutrientes) necessários para o seu crescimento (Rocha et al., 1964), resultando em produção de biomassa reduzida.

No primeiro ano, no espaçamento de $0,60 \mathrm{~m}$ foi proporcionado diâmetro maior que o observado no espaçamento de $0,75 \mathrm{~m}$ (Tabela 2). No espaçamento entre fileiras de $0,60 \mathrm{~m}$ foi proporcionada distribuição mais equidistante das plantas na área, especialmente nas menores populações, o que pode ter reduzido a competição entre estas, com consequente incremento na produção de matéria seca e no diâmetro do caule. Contudo, o diâmetro do caule náo foi alterado pelo espaçamento, no segundo ano do experimento. Com o aumento na população de plantas foi reduzido o diâmetro do caule, independentemente do espaçamento utilizado, nos dois anos de cultivo (Figura 2c,d), o que pode ser explicado pela maior competição entre as plantas por luz na fileira. Com a alteração no arranjo de plantas é afetada a qualidade de luz interceptada e ocasionada maior absorção de luz na faixa do vermelho (V) e maior reflexão na do vermelho extremo (VE). Em plantas que recebem mais luz VE refletida, ou seja, maior relação VE/V, há elongação e afinamento do caule (KAsperbauer e Karlen, 1994). Kittock e Williams (1970) e Severino et al. (2006a) também observaram redução no diâmetro caulinar com o aumento da populaçáo de plantas, pelo aumento no número de plantas na fileira ou pela redução do espaçamento entre fileiras.
A altura média das plantas foi influenciada pelo espaçamento entre fileiras e populaçáo de plantas, em 2008 (Tabela 2). Em 2009, além da influência isolada dos fatores, houve também efeito da interação. Em 2008, constatou-se que, nas plantas submetidas aos espaçamentos mais estreitos $(0,45$ e $0,60 \mathrm{~m})$, as alturas foram maiores. VALE (2009) relatou que, com o uso de espaçamentos entre fileiras mais estreitos, é induzido o crescimento excessivo das plantas em altura, podendo ser superior a $2,0 \mathrm{~m}$, mesmo no material de porte baixo. $\mathrm{O}$ crescimento pode ser mais pronunciado em solos férteis ou bem adubados, especialmente se houver precipitaçóes pluviais elevadas durante o ciclo da cultura (Severino et al., 2006a). Em 2009, a maior altura de plantas foi proporcionada no espaçamento entre fileiras mais largo, que foi diferente apenas dos valores obtidos nos espaçamentos de 0,45 e $0,75 \mathrm{~m}$.

Em 2008, a altura de plantas foi influenciada de forma quadrática pela população de plantas, sendo a menor altura proporcionada na população estimada de 50.000 plantas ha-1 (Figura 3a). Em 2009, com o aumento na população de plantas não foi reduzida a altura das plantas apenas no espaçamento de 0,90 $\mathrm{m}$ entre fileiras (Figura 3b). Assim, na maior população (70.000 plantas ha $\left.{ }^{-1}\right)$, no espaçamento de $0,90 \mathrm{~m}$ entre fileiras, foi proporcionada maior altura de planta que nos demais. A redução na altura das plantas, com o aumento da população, nos espaçamentos mais estreitos, está relacionada à maior 

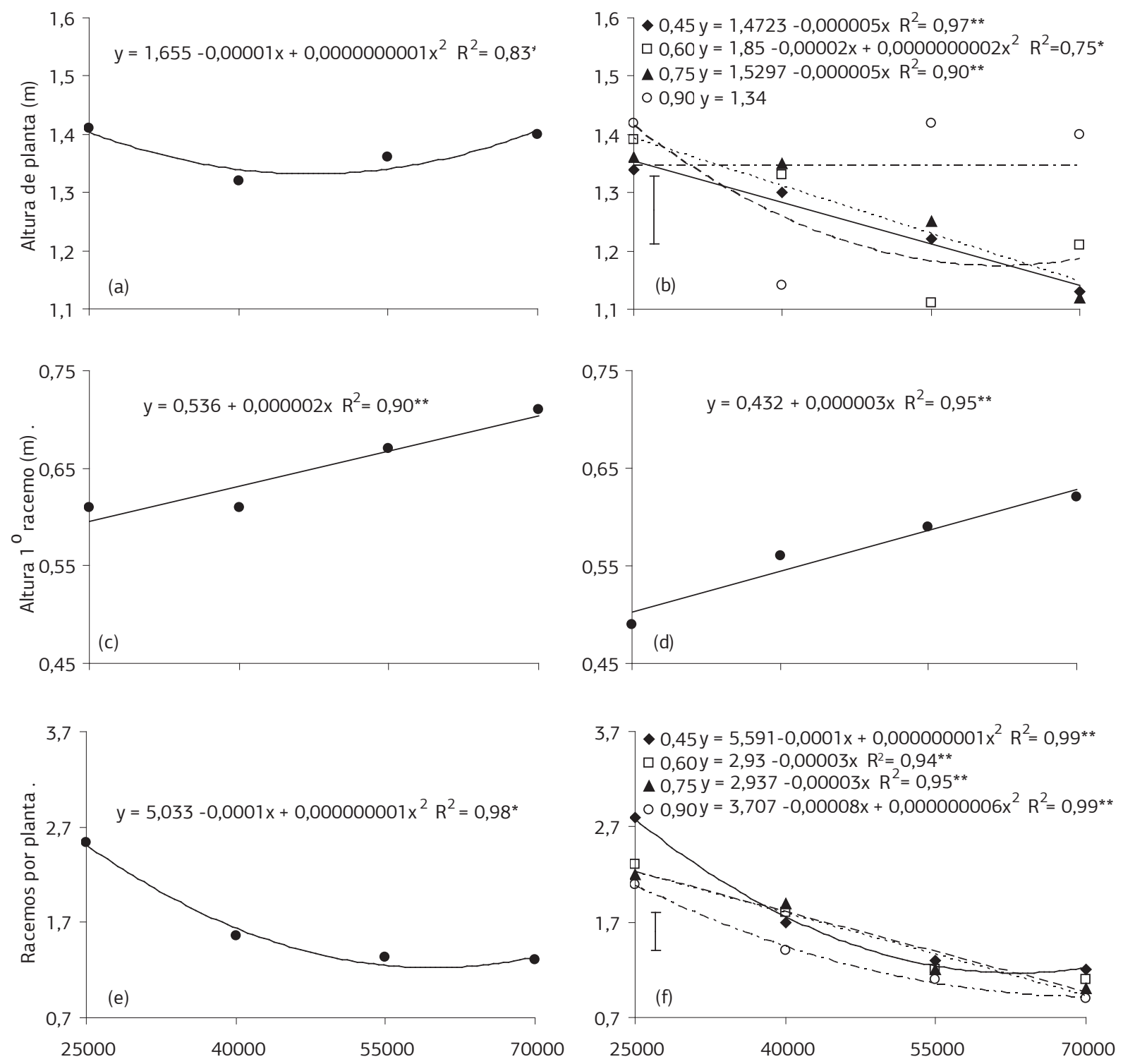

População inicial (plantas ha" ${ }^{-1}$ )

Figura 3. Altura da planta (a,b), altura de inserçâo do $1 .^{\circ}$ racemo (c,d) e número de racemos por planta (e,g) da mamoneira cultivar IAC 2028 em função da população de plantas e espaçamentos entre fileiras, na safrinha. Botucatu (SP), 2008 (a,c,e) e 2009 (b,d,f). Barras verticais são indicativas do valor de DMS pelo teste de Tukey $(\mathrm{p} \leq 0,05)$, para o efeito de espaçamento dentro de populaçáo. ${ }^{*} \mathrm{p}<0,05 .{ }^{* *} \mathrm{p}<0,01$.

competição entre as plantas. Já a ausência de efeito do aumento da população na altura das plantas cultivadas em espaçamento mais largo é decorrente de estiolamento das plantas, uma vez que nestas condiçóes foram constatados menores valores de produção de matéria seca e de diâmetro do caule (Figura 2b,d). Como citado, nas plantas em que a luz refletida é na faixa do VE, ou seja, maior relação VE/V, devido ao maior adensamento, são constatados elongação e afinamento do caule (Kasperbauer e Karlen, 1994). Para a realização da colheita mecanizada na cultura da mamona, é desejável que as plantas tenham caules mais finos e porte baixo (Lopes et al., 2008). Apesar de mais disponibilidade hídrica em 2009 (Figura 1), não foram observados maiores valores de matéria seca, diâmetro do caule e altura das plantas (Tabela 2 e Figuras 2 e 3).
A altura de inserção do primeiro racemo também foi alterada pelo espaçamento entre fileiras e pela população de plantas, no primeiro ano; enquanto, no segundo, houve influência apenas da população de plantas (Tabela 2). Em 2008, as maiores alturas de inserçâo do primeiro racemo foram proporcionadas pelos espaçamentos de 0,45 e 0,60 m entre fileiras. Devido ao incremento da população de plantas, em ambos os anos, foi aumentada linearmente essa variável, sendo os maiores valores observados na população de 70.000 plantas ha $^{-1}$ (Figura 3c,d). Segundo Severino et al. (2006c), a altura de inserção do primeiro racemo é mais influenciada pelo adensamento de plantas que a altura das plantas da mamoneira, devido ao estiolamento do caule. Nas plantas sob maior competição, especialmente por luz, há maior elongaçáo do caule, em detrimento do seu 
diâmetro (Kasperbauer e Karlen, 1994; Severino et al., 2006c; SiLva et al., 2006), como foi observado no presente trabalho. Kiтtock e Williams (1970) determinaram acréscimo na altura de inserçáo do primeiro racemo e redução da altura da planta, com o aumento da população de plantas, no mesmo espaçamento entre fileiras.

O número de racemos por planta foi influenciado apenas pela população de plantas, no primeiro ano, e por ambos os fatores e pela interação, no segundo ano (Tabela 2). Em 2008 , verificou-se que, com o aumento no número de plantas por área, foi reduzido o número de racemos por planta (Figura 3e). Em 2009, devido ao acréscimo na população de plantas também foi reduzido o número de estruturas reprodutivas por planta, porém, no menor espaçamento entre fileiras, especialmente nas menores populaçōes de plantas, foram proporcionados maiores valores dessa variável, provavelmente, pela configuraçâo espacial mais adequada das plantas na área (Figura 3f). Segundo VALE (2009), há tendência para diminuir o número de racemos à medida que é aumentada a populaçáo de plantas, visto que, naquelas plantas mais espaçadas, existe mais área de captação de luz, não havendo interferência ou competição igual às plantas em menores espaços, e, portanto, produção de matéria seca mais elevada e arquitetura produtiva mais adequada, podendo ser expresso seu potencial, na emissão de mais racemos.

O número de frutos por racemo foi influenciado por ambos os fatores estudados e pela interaçáo entre eles ( $\mathrm{Ta}$ bela 3). De maneira geral, em ambos os anos de cultivo, com o aumento da população de plantas foi reduzido o número de frutos por racemo (Figura 4a,b). Contudo, em 2008, na menor população de plantas (25.000 plantas $\left.\mathrm{ha}^{-1}\right)$, o maior número de frutos por racemo foi proporcio- nado no espaçamento entre fileiras de 0,60 m (Figura 4a). Em 2009, o maior valor dessa variável foi observado no espaçamento de $0,90 \mathrm{~m}$ e com 25.000 plantas ha $^{-1}$ (Figura 4b). Nas menores populaçóes de plantas e espaçamentos entre fileiras, em que é proporcionada distribuição mais adequada das plantas na área, é favorecida a produção de racemos com mais frutos, mesmo que as plantas nessas condições também tenham mais racemos, já que existe correlação positiva entre esses componentes (2008: $r=$ 0,54, $\mathrm{p}<0,001$ e 2009: $\mathrm{r}=0,52, \mathrm{p}<0,001)$. Também foram verificadas correlaçôes significativas entre a produção de matéria seca e o número de racemos por planta (2008: $\mathrm{r}=0,75, \mathrm{p}<0,001$ e 2009: $\mathrm{r}=0,70, \mathrm{p}<0,001)$ e o número de frutos por racemo ((2008: $\mathrm{r}=0,73, \mathrm{p}<0,001$ e 2009 : $\mathrm{r}=0,66, \mathrm{p}<0,001)$, indicativo de produção de mais racemos e de frutos por racemos em plantas robustas, ou seja, com quantidade mais elevada de matéria seca.

O número de grãos por frutos não foi alterado pelos fatores estudados (Tabela 3). Este componente da produção é pouco influenciado pelo ambiente, pois é uma característica de elevada herdabilidade (FreIre et al., 2007).

A massa de cem grãos foi influenciada apenas pela população de plantas, nos dois anos de cultivo (Tabela 3), sendo os valores ajustados a uma equação linear, em 2008 (Figura 4c), e quadrática, em 2009 (Figura 4d). Para SANGOI (2000), o decréscimo na massa de cem grãos possivelmente está associado ao aumento da competiçấo intraespecífica provocada pelo aumento da população de plantas. Esse problema pode ser agravado nas situaçóes de desuniformidade de desenvolvimento das plantas, em que as "plantas dominadas" são mais afetadas pelo aumento da população de plantas, demonstrando-se que os efeitos da competição

Tabela 3. Número de frutos por racemo, número de grãos por fruto, massa de 100 grãos, produtividade de grãos, teor de óleo nos grãos e produtividade de óleo da mamoneira cultivar IAC 2028 em funçáo do espaçamento entre fileiras e populaçáo de plantas, na safrinha. Botucatu (SP), 2008 e 2009

\begin{tabular}{|c|c|c|c|c|c|c|c|c|c|c|c|c|}
\hline \multirow{2}{*}{ Tratamentos } & \multicolumn{2}{|c|}{ Frutos por racemo } & \multicolumn{2}{|c|}{$\begin{array}{l}\text { Grãos por } \\
\text { fruto }\end{array}$} & \multicolumn{2}{|c|}{$\begin{array}{l}\text { Massa de } 100 \\
\text { grãos }\end{array}$} & \multicolumn{2}{|c|}{$\begin{array}{l}\text { Produtividade } \\
\text { de grãos }\end{array}$} & \multicolumn{2}{|c|}{$\begin{array}{l}\text { Teor de óleo } \\
\text { nos grãos }\end{array}$} & \multicolumn{2}{|c|}{$\begin{array}{l}\text { Produtividade } \\
\text { de óleo }\end{array}$} \\
\hline & 2008 & 2009 & 2008 & 2009 & 2008 & 2009 & 2008 & 2009 & 2008 & 2009 & 2008 & 2009 \\
\hline Espaçamento (m) & \multicolumn{4}{|c|}{ número } & \multicolumn{2}{|c|}{ g } & \multicolumn{2}{|c|}{$\mathrm{kg} \mathrm{ha}^{-1}$} & \multicolumn{2}{|c|}{$\%$} & \multicolumn{2}{|c|}{$\mathrm{kg} \mathrm{ha}^{-1}$} \\
\hline 0,45 & $26,5 a$ & $16,7 \mathrm{bc}$ & $2,52 \mathrm{a}$ & $2,79 a$ & $48,5 a$ & $52,8 a$ & $2.297 a$ & $1.780 a b$ & $49,2 a$ & $47,4 a$ & $984 a$ & 735ab \\
\hline 0,60 & $27,8 \mathrm{a}$ & $18,1 \mathrm{a}$ & $2,52 \mathrm{a}$ & $2,79 a$ & $47,5 a$ & $54,0 a$ & $2.430 a$ & $1.849 a$ & $48,7 a$ & $48,5 a$ & $1.029 a$ & $781 a$ \\
\hline 0,75 & $23,5 b$ & $16,7 c$ & $2,49 a$ & $2,82 \mathrm{a}$ & $48,1 \mathrm{a}$ & $55,0 a$ & $1.991 b$ & $1.669 \mathrm{bc}$ & $48,0 \mathrm{a}$ & $46,7 a$ & $833 b$ & $681 \mathrm{bc}$ \\
\hline 0,90 & $23,2 b$ & $17,6 a b$ & $2,50 a$ & $2,77 a$ & $48,3 a$ & $55,2 \mathrm{a}$ & $1.871 \mathrm{~b}$ & $1.537 c$ & $48,3 a$ & $45,9 a$ & $787 b$ & $614 c$ \\
\hline \multicolumn{13}{|l|}{ Teste F } \\
\hline Espaçamento (E) & $16,38^{* *}$ & $15,77^{* *}$ & $0,36 n s$ & $1,09 \mathrm{~ns}$ & $0,68 \mathrm{~ns}$ & $1,73 \mathrm{~ns}$ & $45,00^{* *}$ & $12,46^{* *}$ & $0,85 n s$ & $1,81 \mathrm{~ns}$ & $22,47^{* *}$ & $17,82^{* *}$ \\
\hline \multicolumn{13}{|c|}{ População inicial (P) } \\
\hline Reg. Linear & $187,00^{* *}$ & $210,38^{* *}$ & $0,50 \mathrm{~ns}$ & $1,52 \mathrm{~ns}$ & $16,50^{* *}$ & $0,06 n s$ & $3,64 \mathrm{~ns}$ & $3,93 \mathrm{~ns}$ & $3,31 \mathrm{~ns}$ & $3,83 \mathrm{~ns}$ & $4,39 \mathrm{~ns}$ & $0,19 \mathrm{~ns}$ \\
\hline Reg. Quadrática & $8,33^{* *}$ & $1,44 \mathrm{~ns}$ & $0,00 \mathrm{~ns}$ & $0,00 \mathrm{~ns}$ & $1,64 \mathrm{~ns}$ & $5,58^{*}$ & $39,05^{* *}$ & $3,69 \mathrm{~ns}$ & $1,91 \mathrm{~ns}$ & $2,51 \mathrm{~ns}$ & $38,00^{* *}$ & $5,45 \mathrm{~ns}$ \\
\hline$E \times P$ & $5,35^{* *}$ & $12,49^{* *}$ & $1,70 \mathrm{~ns}$ & $1,23 \mathrm{~ns}$ & $1,86 \mathrm{~ns}$ & $0,91 \mathrm{~ns}$ & $2,95^{* *}$ & $6,39 * *$ & $0,59 \mathrm{~ns}$ & $0,83 n s$ & $2,71^{*}$ & $6,10^{* *}$ \\
\hline $\mathrm{CV}_{\text {parcela }}(\%)$ & 8,9 & 4,7 & 4,0 & 2,5 & 4,2 & 6,2 & 7,2 & 9,0 & 5,0 & 5,9 & 10,8 & 9,7 \\
\hline $\mathrm{CV}_{\text {subparcela }}(\%)$ & 8,4 & 4,6 & 6,1 & 3,4 & 3,3 & 3,9 & 10,7 & 8,8 & 2,7 & 6,8 & 11,4 & 10,4 \\
\hline
\end{tabular}

Médias seguidas de letras distintas, na coluna, dentro do fator espaçamento, são diferentes estatisticamente pelo teste de Tukey $(\mathrm{p} \leq 0,05)$. ${ }^{*}=\mathrm{p}<0,05 \mathrm{e}^{* *}=\mathrm{p}<0,01$. ns $=$ năo significativo 

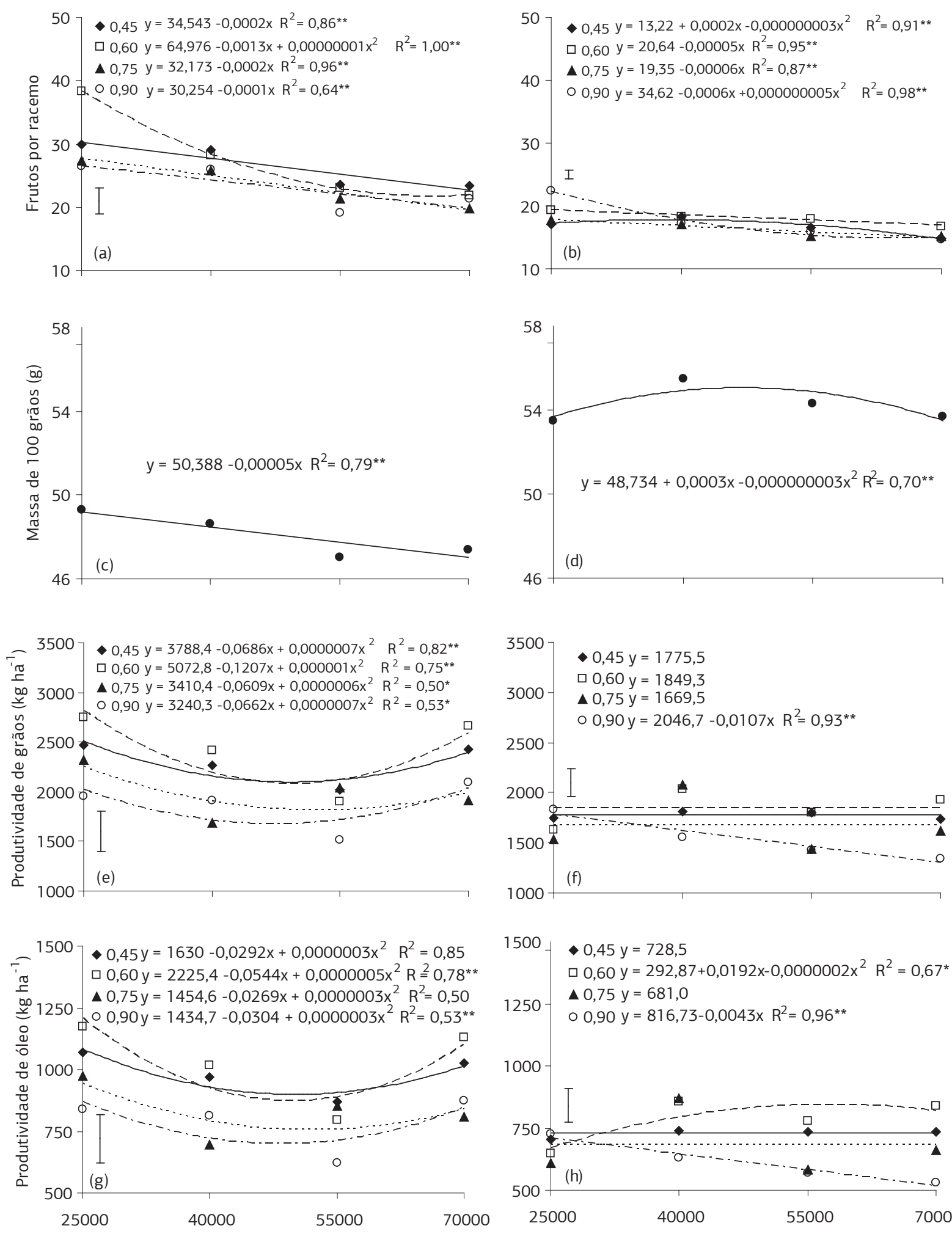

População inicial (plantas ha ${ }^{-1}$ )

Figura 4. Número de frutos por racemo (a,b), massa de 100 grãos $(\mathrm{c}, \mathrm{d})$, produtividade de grãos (e,f) e produtividade de óleo (g,h) da mamoneira cultivar IAC 2028 em função da população de plantas e espaçamentos entre fileiras, na safrinha. Botucatu (SP), 2008 (a,c,e,g) e 2009 (b,d,f,h). Barras verticais são indicativas do valor de DMS pelo teste de Tukey $(p \leq 0,05)$, para o efeito de espaçamento dentro de população. * $\mathrm{p}<0,05 \mathrm{e}^{* *} \mathrm{p}<0,01$. 
intraespecífica ocorrem ou quando as plantas estão em populaçôes mais elevadas ou quando são dominadas por plantas vizinhas emergidas mais rapidamente (MеRотто JUNIOR et al., 1999). É importante ressaltar que, devido à maior quantidade de chuvas ocorridas em 2009, especialmente após o início do florescimento (Figura 1), foram proporcionados maiores valores médios de massa de cem grãos, quando comparadas com as do ano anterior.

Em 2008, a produtividade de grãos foi influenciada pelo espaçamento entre fileiras, população de plantas e a interaçấo entre os fatores (Tabela 3) e, em 2009, não se verificou efeito isolado da populaçáo de plantas. Em ambos os anos, a produtividade de gráos mais elevada (2.430 e $1.849 \mathrm{~kg} \mathrm{ha}^{-1}$ ) foi proporcionada pelo espaçamento de $0,60 \mathrm{~m}$ entre fileiras, porém, sendo diferentes estatisticamente apenas dos espaçamentos mais largos $(0,75$ e 0,90 $\mathrm{m})$. Mediante o desdobramento da interação (Figura 4e), verifica-se que, em 2008, apesar de significativos, os efeitos da população de plantas na produtividade de grão, em um mesmo espaçamento, não foram expressivos; nos espaçamentos mais estreitos, porém, especialmente no de 0,60 $\mathrm{m}$, foi proporcionada maior produtividade de grãos que no espaçamento mais largo $(0,90 \mathrm{~m})$, na maioria das populaçôes estudadas. A pequena alteração na produtividade de grãos, com o aumento na populaçáo de plantas, está relacionada com o efeito compensatório entre a população e os componentes da produção (racemos por planta e frutos por racemos), já que estes foram reduzidos significativamente. Para Rocha et al. (1964), com o aumento da população de plantas é reduzida a produção de grãos por planta de mamona, mesmo que em alguns casos não tenha sido alterada ou mesmo aumentada a produtividade por área. Por outro lado, VALE (2009) observou um incremento linear na produtividade de grãos com o aumento da população de plantas, pela redução no espaçamento entre fileiras da cultura da mamona; contudo, este autor trabalhou com populaçóes menores que as do presente estudo e não observou alterações nos componentes da produção.

Em 2009, devido ao aumento da população de plantas, no espaçamento de $0,90 \mathrm{~m}$ entre fileiras, foi reduzida significativamente a produtividade de grãos (Figura 4f). Nos demais espaçamentos, não houve efeito da populaçáo de planta, provavelmente devido à distribuição mais adequada das plantas na área. Além disso, na maior população $(70.000$ plantas ha $\left.\mathrm{a}^{-1}\right)$, no espaçamento de $0,60 \mathrm{~m}$, a produtividade foi significativamente mais elevada que no de $0,90 \mathrm{~m}$, provavelmente devido à distribuição mais equidistante das plantas na área. Para Rocha et al. (1964), com a aglomeração de plantas na fileira, em funçâo do aumento do espaçamento, em uma mesma população, foi reduzida a produtividade de grãos. Assim, não só a população de plantas é importante, mas também o arranjo delas na área. A produtividade obtidas foi mais elevada que a relatada por SAVY FiLHO et al. (2007), para a cultivar IAC 2028, no período de safrinha, e por SEverino et al. (2006), provavelmente devido aos es- paçamentos entre fileiras mais estreitos e às populaçóes de plantas mais elevadas utilizados no presente trabalho.

$\mathrm{O}$ teor de óleo nos grãos não foi afetado pelos fatores estudados (Tabela 3). Cabe ressaltar que estavam muito próximos do descrito por SAVY Filho et al (2007) para esta cultivar. Segundo Moshrin (1986) e Severino et al. (2006b), o teor de óleo nos grãos da mamoneira é uma característica de elevada herdabilidade. Kiтtock e Williams (1970) também não verificaram alteração no teor de óleo nos grãos da mamoneira submetida a diferentes populaçóes de plantas. Por outro lado, Severino et al. (2006a) verificaram incremento no teor de óleo nos grãos da mamoneira com o aumento do espaçamento entrelinhas. Segundo esses autores, na verdade, a influência dos fatores ambientais e dos tratos culturais no teor de óleo nos grãos da mamoneira é um aspecto ainda pouco compreendido, pois os resultados são divergentes de experimento para experimento. Koutroubas et al. (1999), estudando genótipos de mamona em dois ambientes, por três anos, na Grécia, constataram que o teor de óleo foi variável entre os anos e entre as localidades e que, quando a produtividade foi maior, o teor de óleo foi diminuído, havendo correlação negativa entre os dois fatores. Contudo, no presente estudo, apesar da ausência de efeito dos fatores no teor de óleo, houve correlaçôes positivas entre a produtividade de grãos e o teor de óleo (2008: $r=0,25, p<0,05$ e 2009: $r=0,30, p<0,05$ ).

Como os fatores estudados náo tiveram efeito no teor de óleo, a produtividade de óleo foi influenciada de forma semelhante à produtividade de grãos (Tabela 3), com correlaçôes positivas entre essas variáveis (2008: $r=0,99$, $\mathrm{p}<0,001$ e 2009: $\mathrm{r}=0,95, \mathrm{p}<0,001)$. De maneira geral, no espaçamento $0,60 \mathrm{~m}$ entre fileiras obteve-se produtividade de óleo maior que nos espaçamentos mais largos $(0,75$ e $0,90 \mathrm{~m}$ ), independentemente da população de plantas, no primeiro ano (Figura 4g), e principalmente nas maiores populaçóes, no segundo ano (Figura $4 \mathrm{~h}$ ).

\section{CONCLUSÃO}

$\mathrm{Na}$ safrinha, a produtividade de grãos da mamoneira de porte baixo e de ciclo curto é pouco influenciada pelas populaçóes de plantas estudadas, especialmente nos menores espaçamentos entre fileiras.

A produtividade da mamoneira de ciclo curto IAC 2028, na safrinha, na região de Botucatu (SP), é bastante favorecida nos cultivos em espaçamentos entre fileiras de 0,45 e 0,60 m.

\section{AGRADECIMENTOS}

À FAPESP, pela concessão de bolsa de Mestrado ao primeiro autor e de Iniciação Científica à terceira autora; ao CNPq, pela concessão de bolsa de Produtividade em Pesquisa ao segundo autor. 


\section{REFERÊNCIAS}

AZEVEDO, D.M.P.; BELTRÃO, N.E.M.; SEVERINO, L.S. Manejo cultural. In: AZEVEDO, D.M.P.; BELTRĀO, N.E.M. (Ed.). O agronegócio da mamona no Brasil. 2.ed. rev. e ampl. Campina Grande: Embrapa Algodão, 2007. p.223-253.

BEZERRA, A.A.C.; TAVORA, F.J.A.F.; FREIRE FILHO, F.R.; RIBEIRO, V.Q. Características de dossel e de rendimento em feijão-caupi ereto em diferentes densidades populacionais. Pesquisa Agropecuária Brasileira, v.44, p.1239-1245, 2009.

CAMPOS, H. Estatística aplicada à experimentação com cana-deaçúcar. São Paulo: FEALQ/USP, 1984. 292p.

CANECCHIO FILHO, V. Resultados de experiências com espaçamento da mamoneira anã, variedade I.A. 38. Bragantia, v.13, p.297-305, 1954.

CANECCHIO FILHO, V.; FREIRE, E.S. Adubação da mamoneira. II - Experiências de espaçamento x adubação. Bragantia, v.18, p.77-99, 1959.

COMPANHIA NACIONAL DE ABASTECIMENTO (Brasília, DF). Safras - Série histórica (Mamona). Disponível em: <http:// www.conab.gov.br/OlalaCMS/uploads/arquivos/e1a0861 6d40e0661548424aa59c05146..xls>. Acesso em: 12/2/2010.

EMPRESA BRASILEIRA DE PESQUISA AGROPECUÁRIA. Sistema Brasileiro de Classificação dos Solos. Rio de Janeiro: EMBRAPA/CNPSO, 2006. 412p.

FAO - STATISTICS. Production and trade - Castor beans, 2007. Disponível em: <http://faostat.fao.org >. Acesso em: 9/12/2009.

FREIRE, E.C.; LIMA, E.F; ANDRADE, F.P.; MILANI, M.; NÓBREGA, M.B.M. Melhoramento genético. In: AZEVEDO, D.M.P.; BELTRÃO, N.E.M. (Ed.). O agronegócio da mamona no Brasil. 2.ed. rev. e ampl. Campina Grande: Embrapa Algodão, 2007. p.169-194.

HENDERSON, T.L.; JOHNSON, B.L.; SCHNEITER, A.A. Row spacing, plant population, and cultivar effects on grain amaranth in the northern Great Plains. Agronomy Journal, v.92, p.329-336, 2000.

KASPERBAUER, M.J.; KARLEN, D.L. Plant spacing and reflected far-red light effects on phytochrome-regulated photosynthate allocation in corn seedlings. Crop Science, v.34, p.1564-1569, 1994.

KITTOCK, D.L.; WILLIAMS, J.H. Effects of plant population on castorbean yield. Agronomy Journal, v.62, p.527-529, 1970.

KOUTROUBAS, S.D.; PAPAKOSTA, D.K.; DOITSINIS, A. Adaptation and yielding ability of castor plant (Ricinus communis L.) genotypes in a Mediterranean climate. European Journal of Agronomy, v.11, p.227-237, 1999.

LOPES, F.F.M.; BELTRÃO, N.E.M.; LOPES NETO, J.P.; PEDROZA, J.P. Crescimento inicial de genótipos de mamoneira com sementes submetidas ao envelhecimento acelerado. Revista Brasileira de Oleaginosas e Fibrosas, v.12, p.69-79, 2008.
MEROTTO JUNIOR, A.; SANGOI, L.; ENDER, M.; GUIDOLIN, A.F.; HAVERROTH, H.S. Desuniformidade de emergência reduz o rendimento de grãos de milho. Ciência Rural, v.29, p.595-601, 1999.

MOSHKIN, V.A. Growth and development of the plant. In: MOSHKIN, V.A. (Ed.). Castor. New Delhi: Amerind, 1986. p.36-42.

RAIJ, B. van; ANDRADE, J.C.; CANTARELLA, H.; QUAGGIO, J.A. Análise química para avaliação da fertilidade de solos tropicais. Campinas: Instituto Agronômico, 2001. 285p.

ROCHA, J.L.V.; CONECCHIO FILHO, V.; FREIRE, E.S.; SCARANARI, H.; PETTINELLI, A. Adubação da mamoneira. IV - Experiências de espaçamento x adubação ( $2^{\mathrm{a}}$ série). Bragantia, v.23, p.257-269, 1964.

SANGOI, L. Understanding plant density effects on maize growth and development: an important issue to maximize grain yield. Ciência Rural, v.31, p.159-168, 2000.

SAVY FILHO, A. Mamona: Tecnologia Agrícola. Campinas: EMOPI, 2005. 105p.

SAVY FILHO, A. Mamona. In: RAIJ, B. van; CANTARELA, H.; QUAGGIO, J.A.; FURLANI, A.M.C. Recomendaçōes de adubação e calagem para o Estado de São Paulo. 2.ed. Campinas: Instituto Agronômico e Fundaçáo IAC, 1996. p.201. (Boletim Técnico, 100)

SAVY FILHO, A.; AMORIM, E.P.; RAMOS, N.P.; MARTINS, A.L.M.; CAVICHIOLI, J.C. IAC-2028: nova cultivar de mamona. Pesquisa Agropecuária Brasileira, v.42, p.449-452, 2007.

SEVERINO, L.S.; COELHO, D.K.; MORAES, C.R.A.; GONDIM, T.M.S.; VALE, L.S. Otimização do espaçamento de plantio para a mamoneira cultivar BRS Nordestina. Revista Brasileira de Oleaginosas e Fibrosas, v.10, p.993-999, 2006a.

SEVERINO, L.S.; MILAMI, M.; MORAES, C.R.A.; GONDIM, T.M.S.; CARDOSO, G.D. Avaliação da produtividade e teor de óleo de dez genótipos de mamoneira cultivados em altitude inferior a 300 metros. Revista Ciência Agronômica, v.37, p.188-194, 2006b.

SEVERINO, L.S.; MORAES, C.R.A.; GONDIM, T.M.S.; CARDOSO, G.D.; BELTRĀO, N.E.M. Crescimento e produtividade da mamoneira influenciada por plantio em diferentes espaçamentos entre linhas. Revista Ciência Agronômica, v.37, p.5054, 2006c.

SILVA, S.V.; CHIAVEGATO, E.J.; CARVALHO, L.H.; KUBIAK, D.M. Crescimento e desenvolvimento do algodoeiro em diferentes configuraçōes de semeadura. Bragantia, v.65, p.407-411, 2006.

VALE, L.S. Crescimento e produtividade da mamoneira BRS Energia submetida a diversos espaçamentos. 2009. 31f. Dissertação (Mestrado em Agronomia) - Centro de Ciências Agrárias, Universidade Federal da Paraíba, Campina Grande. 2009. 